\title{
Using Facebook to Enhance Independent Student Engagement: A Case Study of First-Year Undergraduates
}

\author{
Jeff C. Clements ${ }^{1}$ \\ ${ }^{1}$ Department of Biology, University of New Brunswick, Saint John, N.B., Canada \\ Correspondence: Jeff C. Clements, Department of Biology, University of New Brunswick, Saint John, N.B., \\ Canada. Tel.: 1-506-608-8014. E-mail: j.clements@unb.ca \\ Received: June 12, 2015 \\ Accepted: June 23, 2015 \\ Online Published: July 21, 2015 \\ doi:10.5539/hes.v5n4p131 \\ URL: http://dx.doi.org/10.5539/hes.v5n4p131
}

\begin{abstract}
A case study was conducted to assess the efficacy of online communication tools for enhancing independent student engagement in a first-year undergraduate class. Material relevant to course topics was shared with students through three communication platforms and data were extracted to measure student engagement. A questionnaire was also used to validate online data and determine why students chose a particular platform. Online results revealed that more than half of the students engaged with at least one post to some degree through one or more communication platforms. Facebook was the primary platform for student engagement. Students primarily engaged with material on Facebook by "liking" posts and used Facebook to share relevant material that they came across personally. There was no significant difference in student engagement with shared material between instructor-shared and student-shared posts, although Facebook engagement was 29\% higher when the instructor commented and/or liked a post 1 day after sharing. Questionnaire results suggested that $90 \%$ of all students engaged with material to some extent. Most students engaged with between 3 and 10 posts by seeing a post, clicking the associated link, and reading the material. The majority of students engaged through Facebook and felt most comfortable with this platform. Of those engaging at the highest level, $66 \%$ used Facebook. Convenience appeared to be the dominant reason for engaged students choosing a particular platform. Weakly positive relationships between academic performance vs. overall engagement and engagement level were apparent. This study suggests that Facebook can be used to enhance independent student engagement.
\end{abstract}

Keywords: education, Facebook, social media, student engagement, technology

\section{Introduction}

Student engagement is critical for reaching a maximum educational experience at various educational levels (Sharan \& Tan, 2008), as engagement creates a pathway by which student motivation contributes to learning and development (Wellborn, 1991). Generally, three aspects accompany engagement: behaviour, emotion, and cognition. While behavioural engagement is primarily about participation, emotional behaviour relates to the attitudes, values, and interests of students and cognitive behaviour is associated with student goals and student driven learning (Sharan \& Tan, 2008). Consequently, the depth of engagement and the associated impact on learning are a function of the degree that each of the aforementioned aspects of engagement is incorporated by a student.

The application of independent student engagement (defined here as extra-curricular student engagement with material beyond that mandatory for course requirements) has received relatively little attention in higher education. This may be because getting students independently engaged with material can be quite difficult and is often ignored for various reasons, including, but not limited to, student apathy and increased instructor workload. However, with modern advances in technology, such engagement outside of core course requirements can be attained far more easily. Ultimately, using such technology to elevate student engagement can foster positive intellectual and emotional learning attitudes, potentially enhance academic achievement and critical thinking skills (Carini, Kuh, \& Klein, 2006), and have a lasting impression on students' academic experience beyond the scope of achievement scores (Fredricks, Blumenfield, \& Paris, 2004).

Engaging with material and discussions through online tools can aid in the development of student reflection and critical thinking (Burge, 1994; Whipp, 2003; Barnett-Queen, Blair, \& Merrik, 2005; Chang, 2006). Furthermore, online communication tools allow for expedited and easy communication between educators and students, with students relying heavily on online tools both personally and professionally (Mori, 2007; Jones \& Fox, 2009). 
Although most higher education professionals communicate course content through e-mail and/or learning management systems (e.g., Desire2Learn, Blackboard, Moodle, WebCT, etc.), the advent of social media has provided an additional outlet for student-instructor communication, as well a teaching and learning tool in general (Greenhow, Robelia, \& Hughes, 2009). While many educators use social media personally (Moran, Seaman, \& Tinti-Kane, 2011), various issues have led to instructor hesitation in utilizing social media as a learning environment (Cloete, De Villers, \& Roodt, 2009; Manca \& Ranieri, 2013). However, social media can be beneficial as online learning environments by supplementing institutional learning management systems (Nemec, Holb, Burkeljca, \& Welzer, 2011; Said, Tahir, \& Ali, 2014).

One social media platform that can be used for teaching purposes is Facebook. Facebook has received much attention regarding its role as an educational tool (Aydin, 2012). Although most often viewed as a social tool rather than a formal educational tool (Greenhow \& Robelia, 2009; Selwyn, 2009; Usluel \& Mazman, 2009), Facebook can be of benefit to educators in a variety of ways. For example, Facebook can act as a rapid avenue of communication between educators and students, with students often receiving instructor and classmate messages through Facebook far quicker than through other online communication platforms (Sturges, 2011). The high degree of familiarity that students have with Facebook also makes it an effective learning environment (Nemec et al., 2011) and may help students relate to course concepts in a more efficient and engaging way (Pemberton, 2011). Furthermore, educational benefits of Facebook do exist in certain situations, although challenges are evident as well (Souleles, 2012a, b).

The effects of Facebook on student engagement have been documented in a few studies, suggesting both negative and positive impacts. Kirschner and Karpinski (2010) reported that Facebook use amongst students resulted in lower GPA and time investment into academic endeavours. Junco (2011) reported that increased time spent on Facebook was negatively associated with engagement scale scores, although he noted that different aspects of Facebook resulted in different impacts (positive or negative) on student engagement. Positive effects of Facebook use on in-class engagement have also been documented (Wang, Lin, Yu, \& Wu, 2013). Although using Facebook without instructor guidance doesn't promote academic engagement (Wise, Skues, \& Williams, 2011), online student engagement in distance education settings where instructors are involved can be increased using Facebook (Esteves, 2012). Furthermore, since students prefer the educational use of social media to be informal (Cain \& Policastri, 2011; Chen \& Bryer, 2012), Facebook may also be used to optimize independent, extra-curricular student engagement. However, the efficacy of Facebook for enhancing the independent engagement of university students outside of core course requirements has yet to be quantitatively assessed.

Given that Facebook can serve positive roles in student engagement and academic experience, coupled with the fact that Facebook's impact on independent student engagement has received little attention, this study aimed to assess the efficacy of Facebook, in comparison to two other online communication tools, for enhancing independent student engagement in a first-year undergraduate class. Material relevant to course topics was shared with all students through three communication platforms-e-mail, Desire2Learn discussions, and Facebook. Quantitative data were extracted from each platform to measure the frequency of engagement and the level at which students engaged with additional material. A questionnaire was also used to validate the online data and determine why students chose a particular platform.

\section{Method}

\subsection{Ethics Statement}

This was an independent study and was not funded. Prior to data collection, this study was approved by the Research Ethics Board (REB File Number: 007-2015) at the University of New Brunswick Saint John (UNBSJ). Participants provided written informed consent prior to the study. To ensure that data could not be traced back to individual students, no personal information from participants was collected, the Facebook group (see section 2.2) was deleted upon completion of the project, and the questionnaires (see section 2.3) were submitted anonymously.

\subsection{Experimental Description}

During the Winter 2015 semester (January-April, 2015), a case study was conducted with students in the Biology 1202 (BIOL1202: Introduction to Marine Science) course to quantify the efficacy of online communication tools for enhancing independent student engagement. Additional online material (relevant to course) was shared with all BIOL1202 students through two communication platforms: institutional e-mail, Desire2Learn (D2L; learning management system) discussions. For those students interested, a course-specific Facebook group created by the instructor was also used to share additional material. 
In contrast to e-mail and D2L, there were some privacy concerns for Facebook. To address these concerns, the Facebook group setting was set to "closed", in which the group administrator (course instructor) could control who was able join, participate, and post material in the group. Only students enrolled in the BIOL 1202 class were permitted to join the group; students who withdrew from the course were immediately removed from the group. Facebook posts could be viewed only by its group members, and members of the group were not permitted to share posts from the group page (an honoured guideline, not a specific setting).

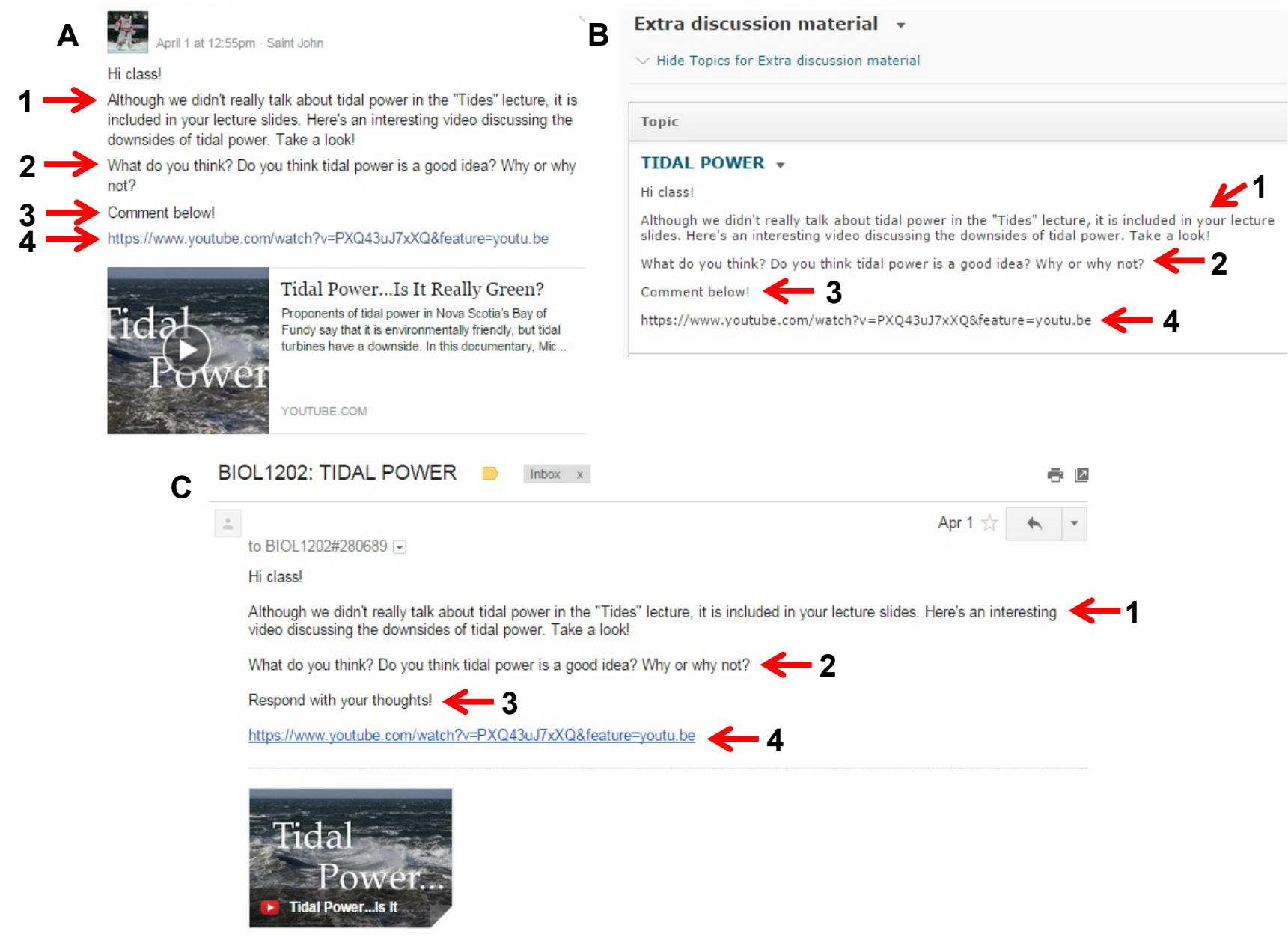

Figure 1. Screenshots of an instructor-shared post of additional material shared on Facebook (A), D2L Discussions (B), and e-mail (C). Arrows highlight the 4 key components of each instructor-shared post: an instructor comment (1), probing questions to help guide critical thinking and student responses (2), a line to encourage engagement (3), and a URL link to additional information regarding a course topic (4)

While students were free to engage with the additional material through any communication platform, engagement with additional material was completely voluntary, was not associated with any bonus marks, and had no impact on a student's grade. Each post of extra material contained a URL link to additional information regarding a course topic along with an instructor comment, probing questions to help guide critical thinking and student responses, and a statement to encourage engagement; these components were identical across all three platforms (Figure 1).

\subsection{Data Collection and Analyses}

\subsubsection{Online Data}

The extent of student engagement with additional material was quantified on each platform using the metrics available through each platform. An additional questionnaire was used to validate trends in the online data (see Section 2.3.2). 
Invitations to engage were sent/posted on e-mail, D2L and Facebook, and units of engagement were quantified as topic-relevant responses on that platform or as face-to-face interactions, during which the student identified the origin (i.e., platform) of the material. For email posts, the units of engagement were limited to the number of responses and face-to-face interactions. Responses to D2L discussions included the number of students who read posts, the number replies within a thread, and face-to-face interactions. On Facebook, engagement units included likes, comments, student posts, and face-to-face interactions. Responses to any platform that were not relevant to the shared material were not included. For example, if a student responded to an e-mail or post containing additional material with a question about course logistics (e.g., test date), it was not included in the analyses.

Given the diverse array of possible units of engagement on Facebook, an engagement index (EI) - a measure of engagement depth - was calculated for each student since the metrics of engagement on Facebook represent different levels of engagement. Likes (seeing and/or reading, but not necessarily thinking critically) can be considered a lower depth of engagement than comments (seeing, reading, and critically thinking). Student posts (finding/seeing, reading, critically thinking, and sharing with class) can be considered the highest level of engagement. I derived a formula to calculate a particular student's overall level of engagement by taking into account the level and frequency of engagement. Thus, EI was calculated for each engaged student as,

$E I=[(1 \times \#$ likes $)+(2 \times \#$ comments $)+(3 \times \#$ posts $)] /$ Total \# Facebook posts

where "likes" is an individual student's total number of likes on instructor and student posts, "comments" is an individual student's total number of comments on instructor and student posts, and "posts" is the total number of posts that an individual shared on the Facebook page; "total number of Facebook posts" represents the total number of instructor and student posts combined.

\subsubsection{Questionnaire Data}

All students received a questionnaire during the final exam, which they submitted anonymously. The purpose of the questionnaire was two-fold: (1) to accompany and validate the online data (given that the quantitative metrics were not consistent across platforms); and (2) to understand why certain platforms may work better than others for enhancing student engagement.

\subsubsection{Facebook Engagement and Academic Performance}

To determine if there was a relationship between student engagement and academic performance, the total number of engagement instances and the EIs of individual students were assessed as a function of course grade and cumulative GPA. Although causal relationships were not determinable, such correlations can provide insight into the importance of engagement on academic performance or vice versa.

\subsubsection{Additional Facebook Metrics}

To assess the impact of follow-up instructor engagement on overall student engagement, I further engaged with half the Facebook posts (liked or commented on) one day after they were shared. Additionally, the platform used by each student engaging at the highest level was recorded. Average engagement per post and overall engagement were compared for instructor-shared vs. student-shared posts as well.

\subsubsection{Statistical Analyses}

All statistical analyses were conducted using R version 2.15.2 (R Development Core Team, 2012) with a significance level of $\alpha \leq 0.05$. Analysis of variance was used to detect differences in the average number of engagement instances per post between the three communication platforms, while a Tukey HSD post-hoc test (with Bonferroni correction) was used to determine individual significance. Student t-tests compared engagement instances between instructor-shared and student-shared posts, as well as engagement instances between posts that received further engagement by the instructor and posts that did not. Linear regression was used to test for significant relationships between individual student engagement (measured as that total number of engagement instances and EI) and academic performance (measured as cumulative GPA and final course grade).

For ANOVA, assumptions of normality and homoscedasticity were tested using Q-Q plots and Bartlett's tests, respectively, while normality for t-tests was tested using Q-Q plots. For regression analyses, assumptions of linearity, normality, and homoscedasticity were tested using component-residual plots, Q-Q plots, and non-constant error variance tests, respectively. No data violated the assumptions of their respective statistical tests. 


\section{Results}

\subsection{Online Results}

\subsubsection{General Engagement}

A total of 26 posts were shared by the instructor on each of the three communication platforms. More than half of the students engaged with at least one post to some degree through one or more of the communication platforms ( 23 students; $58 \%$ ), while 33\% (13 students) of the class engaged with $\geq 4$ posts.

Facebook emerged as the primary platform for student engagement. Total engagement via Facebook was more than 10 fold higher than any other platform (Figure 2A). ANOVA yielded significant differences in average engagement per post between platforms $\left(\mathrm{F}_{2,77}=30.59, \mathrm{P}<0.0001\right)$, while a Tukey HSD post-hoc test revealed highest engagement on Facebook and lowest on D2L (Figure 2B).
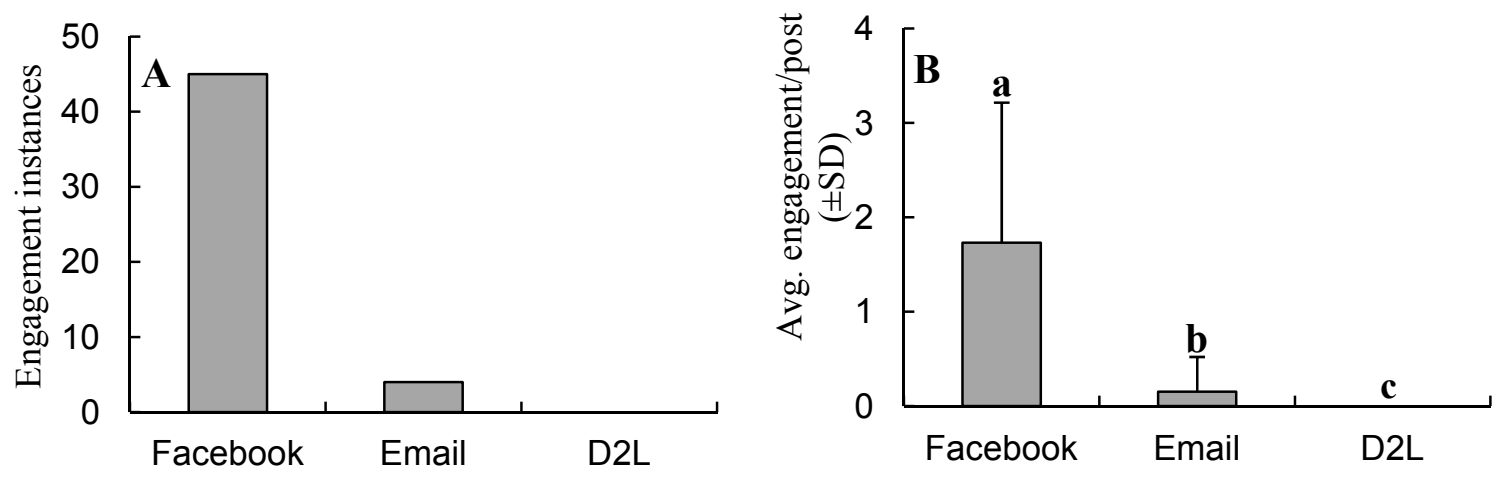

\section{Platform}

Figure 2. The total number of student engagement instances (A) and the average number of student engagement instances per post (B) on each of the three communication platforms. Letters above error bars represent the results of Tukey HSD post-hoc test

\subsubsection{Facebook Engagement}

Students primarily engaged with material on Facebook by "liking" posts (71 likes), although commenting with personal thoughts on posts was observed regularly (20 comments), as well as independently posting relevant material (18 posts). Instructor posts received a total of 32 likes, 11 relevant comments, and 2 face-to-face interactions (a total of 45 instances of engagement). Only 4 students engaged via e-mail, 3 of which responded to an e-mail post and 1 engaging in a face-to-face conversation. Students did not engage with additional material through D2L in any capacity (responses or face-to-face interactions; Figure 2A, B). 

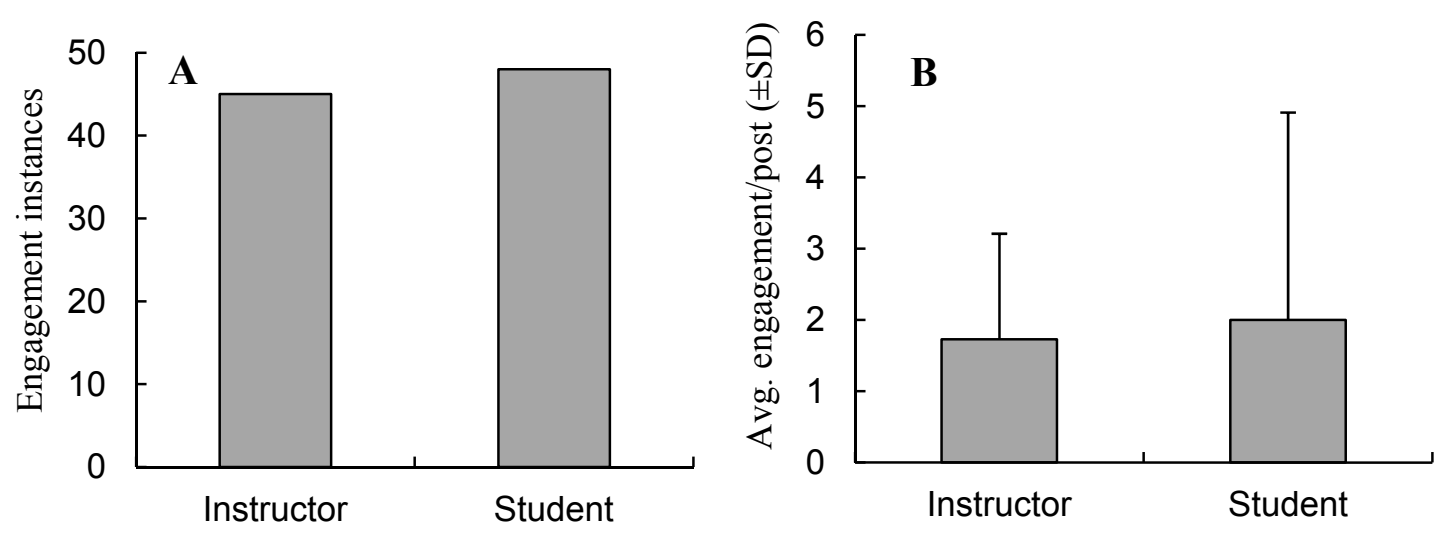

\section{Sharer}

Figure 3. The total number of students engaged (A) and the average number of student engagement instances per post (B) on Facebook posts shared by either the instructor or a fellow student

Unlike e-mail and D2L, students not only utilized the Facebook group to engage with instructor-shared material, but also used it to share additional relevant material. A total of 18 links relevant to course material were shared by 9 students. There was no significant difference in student engagement with shared material between instructor-shared and student-shared posts (Student's t-test: $\mathrm{t}_{25}=-0.4, \mathrm{P}=0.69$; Figure 3A, B).

Follow-up instructor engagement appeared to enhance student engagement with additional material. The total number of students engaging with material on Facebook was 29\% higher when the instructor commented and/or liked a post (Figure 4A). The trend was similar for the average number of students engaging per post, though not significant (Student's t-test: $\mathrm{t}_{11}=1.33, P=0.21$; Figure 4B).
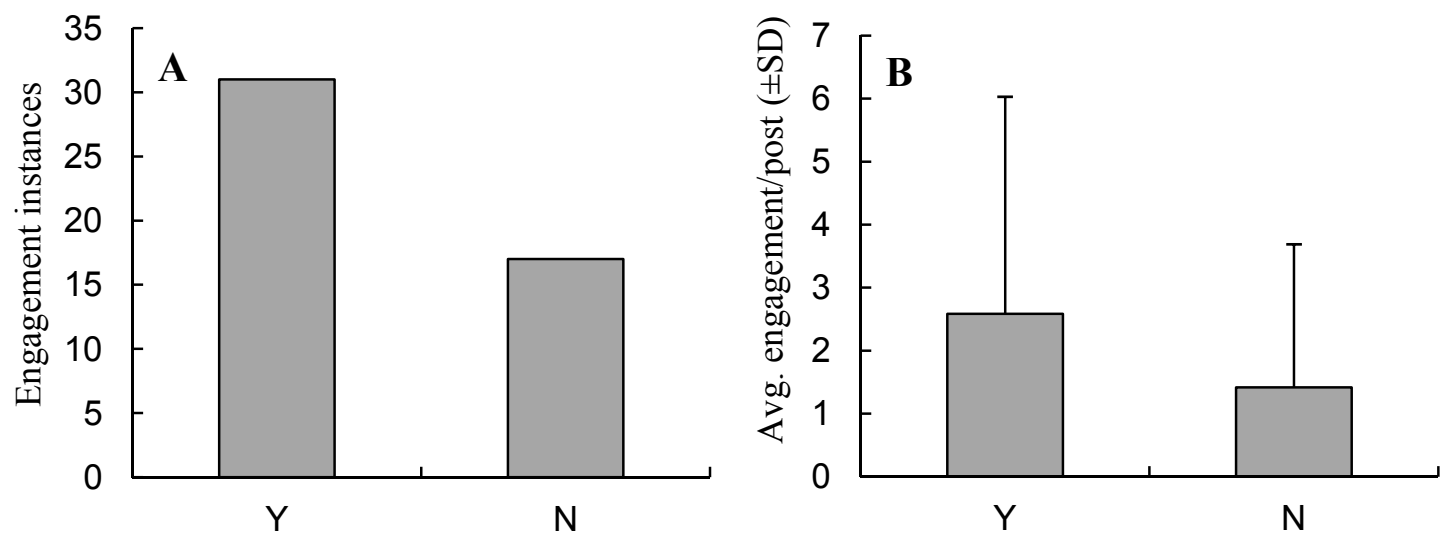

\section{Instructor engagement}

Figure 4. The total number of students engaged (A) and the average number of student engagement instances per post (B) on Facebook posts in which the instructor engaged (Y; liked or commented) or did not engage with (N)

The number of students posting and the total number of posts was highest for first-year students (Figure 5A, B), while the average number of posts per student was highest amongst the oldest academic year class (Figure 5C). Average engagement index tended to increase as academic year increased, with the exception of 4th year students (Figure 5D). Caution should be taken in the interpretation of these results, however, given that the class 
was predominantly first year students and sample sizes for later-year engaged students was low (only 1-2 students).

\subsection{Questionnaire Results}

Values reported in this section are a reflection of all students who answered a given question on the questionnaire. According to the questionnaire, overall student engagement was quite high, with $90 \%$ of all students claiming to have engaged with material to some extent (Table 1). Of those students that claimed to independently engage with shared material, the majority (56\%) engaged only with some of the material (3 to 10 posts), while $19 \%$ and $25 \%$ engaged with most $(>10)$ and few (1-2) posts, respectively (Table 1). With respect to the depth of engagement, the majority of students $(75 \%)$ claimed to have engaged with material by seeing, clicking, and reading posts (Table 1). Furthermore, 17\% claimed to have engaged to the fullest extent by seeing, clicking, reading, and commenting/responding to posts, while $8 \%$ of engagers failed to read any of the additional content (either saw and clicked or simply saw posts) (Table 1).

Of those students who claimed to have engaged to some degree (engaged students) with additional material, $50 \%$ said that they used Facebook to engage with material, while 25\% used a combination of Facebook and e-mail (Table 1). D2L and e-mail were used in isolation by $5.5 \%$ and $19 \%$ of engaged students, respectively (Table 1). With respect to comfort, 53\% of engaged students felt most comfortable engaging with material through Facebook and $30.5 \%$ felt that e-mail was most comfortable; only $2.5 \%$ felt D2L was most comfortable, while $14 \%$ felt comfortable using either Facebook or e-mail (Table 1).
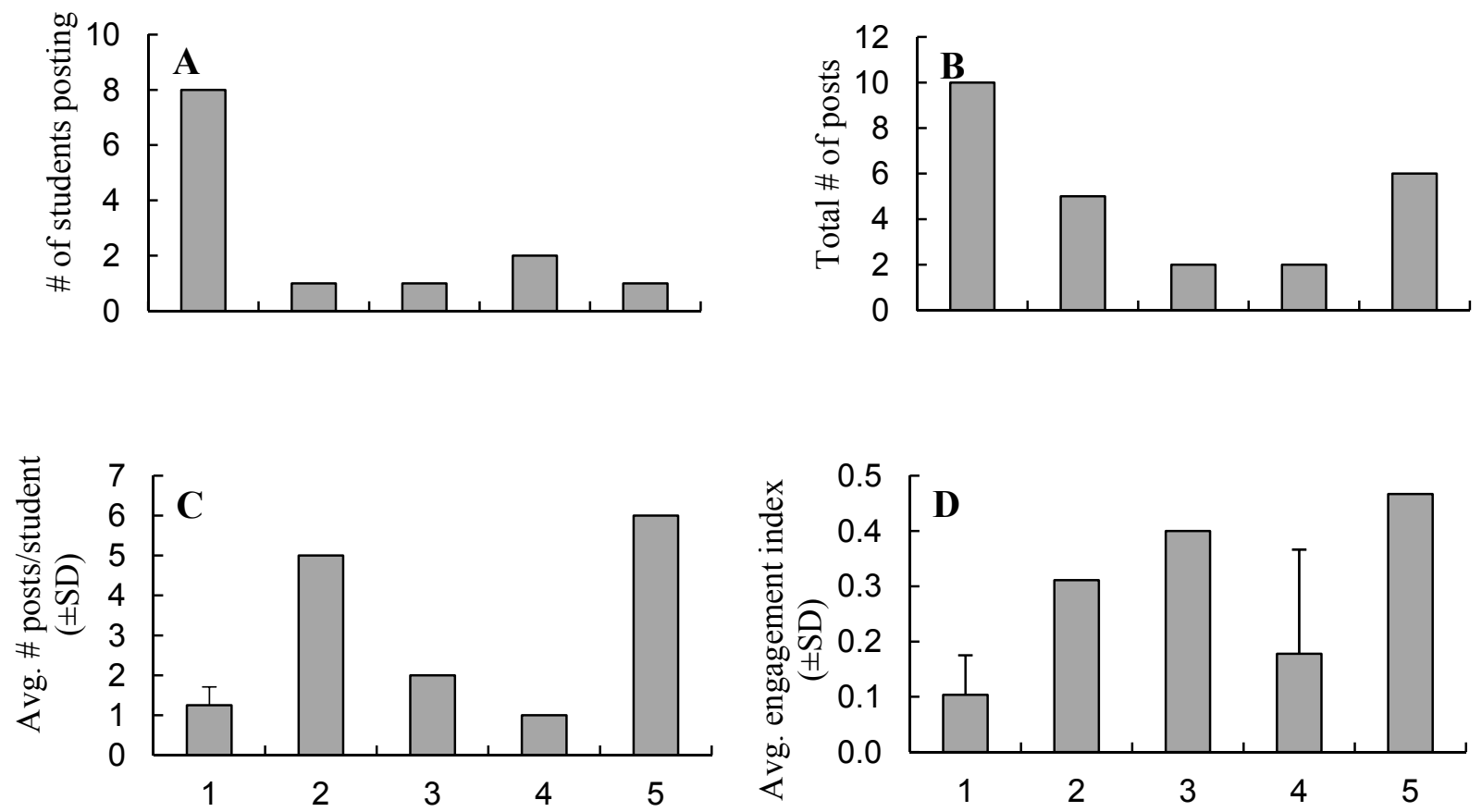

\section{Academic year class}

Figure 5. The total number of students who posted at least one Facebook post (A), the total number of Facebook posts shared by students (B), the average number of posts per student (C), and the average engagement index (D) of students across each of the five academic year classes represented in the course

In general, more engaged students claimed to use Facebook and e-mail than D2L. Platform usage frequency was similar for Facebook and e-mail, with $70 \%$ and $71 \%$ of students using Facebook and e-mail, respectively, checking their respective platform more than once a day (Table 1). Facebook and e-mail were checked once a day by $22 \%$ and $29 \%$ of the students engaging through those platforms, respectively, while only $8 \%$ of students engaging through Facebook checked their account less than daily (Table 1). Furthermore, of those students 
engaging at the highest level (in the questionnaire; saw, clicked, read, and responded), $66 \%$ used Facebook to engage with material, while $34 \%$ used either e-mail alone (17\%) or a combination of Facebook and e-mail (17\%); none of the students engaging at the highest level used D2L (Figure 6).

Convenience appeared to be the dominant reason for engaged students choosing a particular platform (90\%) (Figure 7). Familiarity and comfort also appeared important in platform choice, accounting for $36 \%$ and $28 \%$ of responses, respectively (Figure 7). Furthermore, of those students using Facebook and/or e-mail to engage, convenience appeared most important in choosing that platform, again followed by familiarity and comfort (Table 1). However, for students using D2L, familiarity appeared most important in choosing D2L, followed by convenience and comfort (Table 1$)$. Only 1 student $(2 \%)$ cited a completely different reason for choosing a particular platform (Facebook), stating that the images accompanying the Facebook posts could inform him/her as to whether or not the post was interesting and relevant.

Although mobile notifications are available for all three communication platforms, far more students received mobile notifications from Facebook than both e-mail and D2L. Of those students who engaged, $81 \%$ subscribed to Facebook mobile notifications, while $48 \%$ and $24 \%$ of students subscribed to mobile notifications for e-mail and D2L, respectively (Table 1).

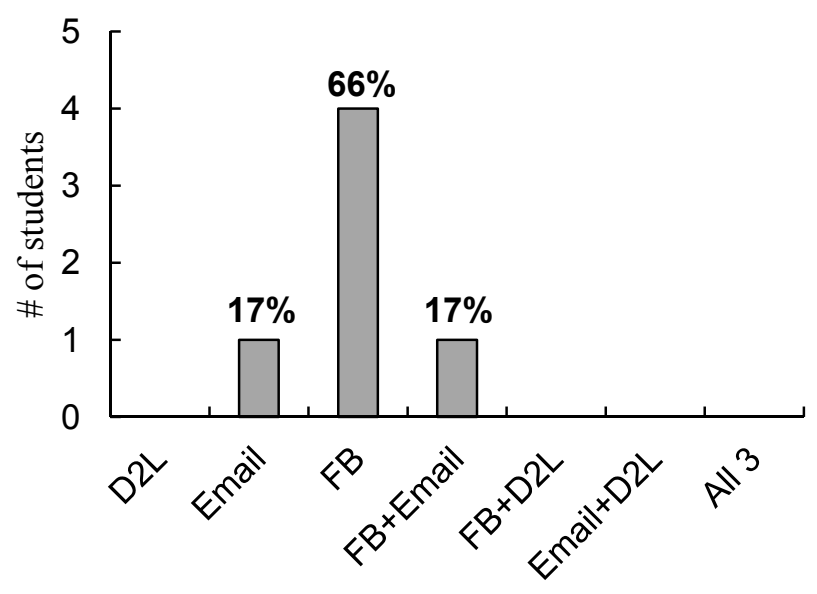

Platform

Figure 6. The total number (and associated percentage) of students engaging at the highest level (saw, clicked, read, and responded) using each of, or a combination of, the 3 communication platforms to engage with material

$$
(\mathrm{n}=7)
$$

\subsection{Facebook Engagement and Academic Performance}

Academic performance was not significantly related to overall engagement or the level of engagement (EI) on Facebook, although a positive trend was apparent in all cases. A weakly positive relationship between student academic performance and the total number of engagement instances existed, however these relationships were insignificant (Figure 8A-D). Similarly, a weakly positive relationship between academic performance and EI existed. Cumulative GPA and course grade accounted for $12 \%$ and $6 \%$, respectively, of the variation in total engagement instances, and 15\% and 16\%, respectively, of the variation in EI (Figure 8C, D). 


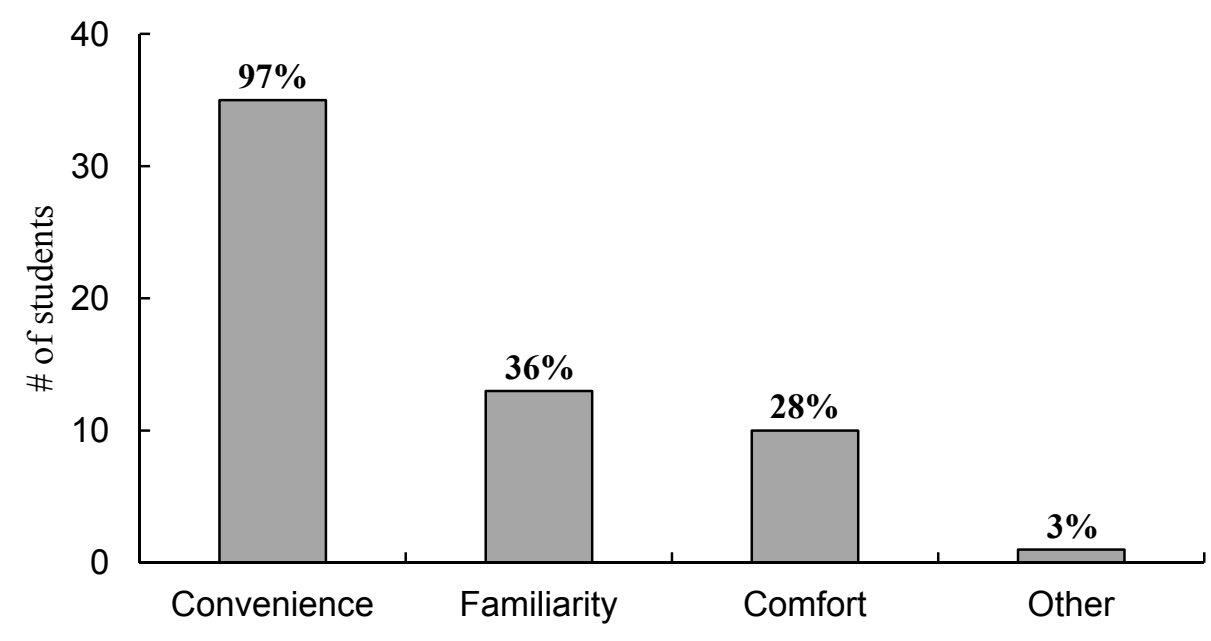

Reason

Figure 7. The total number of students selecting each of 4 reasons for choosing a particular platform to engage with additional material $(n=59$; students could choose more than one response). Percentages represent the percentage of engaged students ( 36 students) choosing the associated response

Table 1. Summary of qualitative questionnaire results

\begin{tabular}{lll}
\hline Question \& response choice & \# of student responses & \% of student responses \\
\hline General engagement & & \\
1. Did you engage? $(\mathrm{n}=40)$ & 36 & $90 \%$ \\
Yes & 4 & $10 \%$ \\
No & & \\
2. Amount of engagement ( $=36)$ & 0 & $0 \%$ \\
All & 7 & $19 \%$ \\
Most & 20 & $56 \%$ \\
Some & 9 & $25 \%$ \\
Only 1 or 2 & & \\
Saw, clicked, read, \& responded & 6 & $17 \%$ \\
Saw, clicked, \& read & 27 & $75 \%$ \\
Saw \& clicked & 2 & $5.5 \%$ \\
Saw & 1 & $2.5 \%$ \\
3. Extent of engagement $(\mathrm{n}=36)$ & & \\
E-mail & 2 & $5.5 \%$ \\
D2L Discussion & 7 & $19 \%$ \\
Facebook group & 18 & $50 \%$ \\
Combination & 9 & $25 \%$ \\
E-mail & 1 & \\
D2L Discussion & 11 & $2.5 \%$ \\
Facebook group & 19 & $30.5 \%$ \\
Combination & 5 & $53 \%$ \\
4. Communication platform (n $=36)$ & & $14 \%$ \\
\hline 5. Most comfortable platform $(\mathrm{n}=36)$ & &
\end{tabular}




\section{Facebook}

6. Frequency of use $(n=27)$

Multiple times per day 19

$70 \%$

Daily

6

$22 \%$

A few times a week

$4 \%$

A few times a month

1

$4 \%$

7. Mobile notifications $(n=27)$

Yes

$81 \%$

No

5

$19 \%$

8. Why Facebook? $(\mathrm{n}=36)$

Convenience

$64 \%$

Familiarity

7

$19 \%$

Comfort

$14 \%$

Other

$3 \%$

\section{Email}

9. Frequency of use $(n=7)$

Multiple times per day

$71 \%$

Daily

A few times a week

$0 \%$

A few times a month

0

$0 \%$

10. Mobile notifications $(n=33)$

Yes

No

11. Why E-mail? $(\mathrm{n}=18)$

Convenience

$61 \%$

Familiarity

$22 \%$

Comfort

Other

$0 \%$

\section{D2L Discussions}

12. Frequency of use $(n=4)$

Multiple times per day

Daily

0

2

A few times a week

2

A few times a month

$0 \%$

$50 \%$

$50 \%$

$0 \%$

13. Mobile notifications $(n=34)$

Yes

14. Why D2L? $(\mathrm{n}=4)$

Convenience

$24 \%$

26

$76 \%$

Familiarity

Comfort

Other
1

2

$25 \%$

$50 \%$

1

0
$25 \%$

$0 \%$ 


\section{Discussion}

The results of this study suggest that Facebook is a useful tool for enhancing independent student engagement, as the amount and depth of engagement was highest for students engaging through Facebook compared to e-mail and D2L. The positive effects of Facebook on student engagement have also been documented by Wang et al. (2013) and Esteves (2012), although negative impacts of Facebook on engagement have been documented by others (Junco, 2011; Wise et al., 2011). Students are thought to be engaging at the highest level when they are engaging behaviourally, emotionally, and intellectually (Sharan \& Tan, 2008). Given that the majority of students reported that they engaged by seeing, clicking, and reading a post, the majority of these students engaged with material primarily behaviourally; their intellectual engagement cannot be determined from these data. However, Facebook allowed 9 students (23\%) to engage at the highest level by sharing material that they personally identified, read and thought about, and posted independently with their own thoughts (encompassing all three aspects of engagement), suggesting an enhanced degree of engagement. This finding is even more impressive in light of the fact that students were not given any grade reward for engaging with additional material. It has previously been reported that undergraduate students preferred Facebook over WebCT (Schroeder \& Greenhouse, 2009) and Moodle (Deng \& Tavares, 2013) to engage with online discussions. Given that more rigorous or substantiated engagement can lead to increased involvement with material (Coates, 2006), providing bonus marks or a participation mark for independent engagement through Facebook may help to maximize student engagement at the highest level and further enhance comprehension. Ultimately, since engaging with material and discussions through online tools such as Facebook can aid in the development of student reflection and critical thinking (Burge, 1994; Whipp, 2003; Barnett-Queen et al., 2005; Chang, 2006), Facebook may aid in the enhancement of these skills in situations where Facebook is an optimal engagement tool.

Given three detailed reasons for choosing a platform and an option to suggest other reasons on the questionnaire, students overwhelmingly cited convenience as the reason for using a particular platform. This finding not only has implications for using Facebook as a tool to enhance independent engagement, but provides insight into how an instructor, in general, can choose a platform to enhance engagement. For example, if the majority of a class does not use Facebook, then Facebook may not be an optimal tool for enhancing engagement in that instance. Instead, it would be most useful to choose a platform that the majority of the class is already engaged with on a regular basis. Although familiarity and comfort appeared to be important for some students, these reasons were cited far less than convenience. One student also cited the presence of images with the posts on Facebook for motivating them to engage, as the image provided insight into whether or not the post would be of interest to the student. Ultimately, a detailed understanding of class demographics with respect to online presence can help isolate a best-candidate platform for enhancing independent engagement in a given situation.

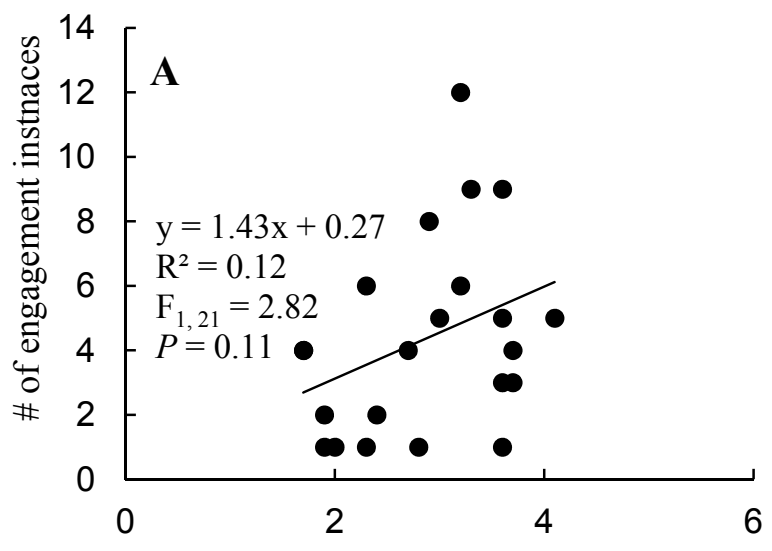

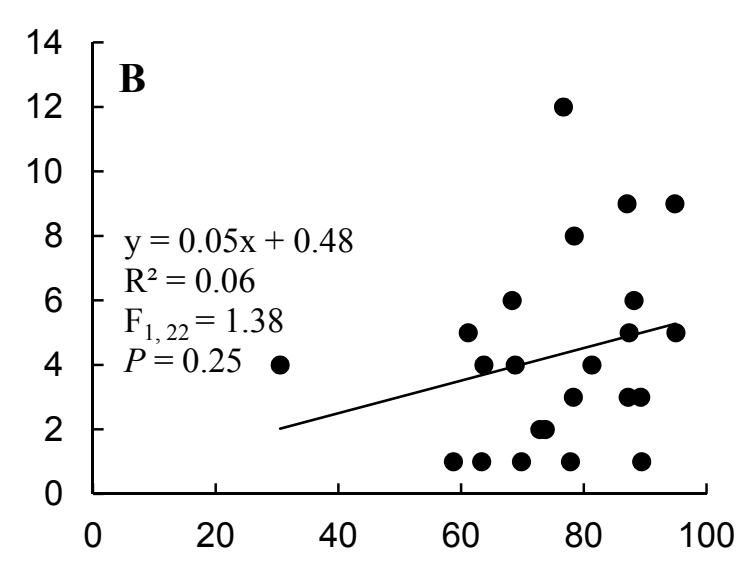




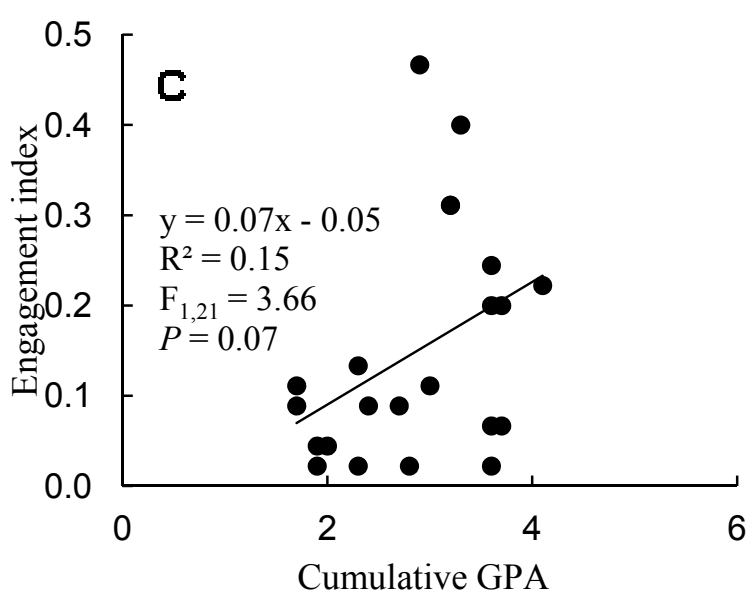

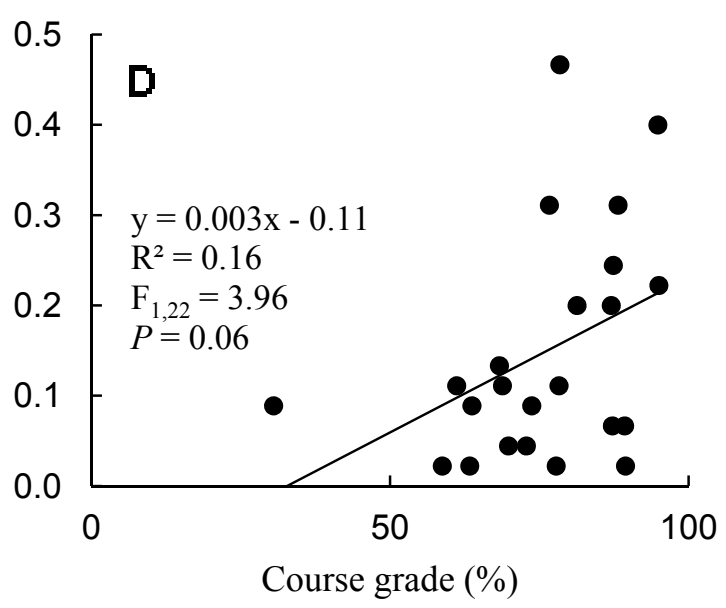

Figure 8. The relationship between the total number of Facebook engagement instances by individual students and their cumulative GPA (A), and final course grade (B), and between the respective engagement index of individual students and their cumulative GPA (C), and final course grade (D)

Independent engagement has been suggested to be a passive process, with students typically showing low social and academic involvement with course material when required to engage independently (Coates, 2006). However, the positive correlations between academic performance and the amount and depth of engagement through Facebook observed here suggest otherwise. It has been reported that intense engagement may be more beneficial for increasing learning than independent, passive engagement (Coates, 2006). Thus, implementing Facebook as a rigorous, mandatory engagement platform may further elevate engagement and learning. However, this is speculative at best and requires more insight. Such an implementation may also be detrimental, as it could diminish the enjoyment of students engaging with material independently through Facebook. Multiple students expressed their pleasure with the Facebook group and its laid-back approach to presenting and engaging with material. Indeed studies have reported that Facebook serves well as an informal learning environment rather than a more formal environment (Cain \& Policastri, 2011; Chen \& Bryer, 2012) and so it is unlikely that the strict, mandatory use of Facebook would be beneficial for enhancing learning through student engagement.

One of the biggest benefits to using Facebook as an educational tool for enhancing student engagement and learning lies in its application to social learning theory (SLT). SLT suggests that learning occurs in both a cognitive and social context and that the incorporation of both contexts is necessary to maximize learning (Bandura, 1977). Furthermore, SLT suggests that learners benefit from engaging directly with fellow learners, direct reinforcement, and being active recipients and providers of information (Bandura, 1977). Given that students on the Facebook group who are sharing and commenting on information are receiving all three beneficial aspects of SLT, a high degree of learning can be fostered. Although students are able to engage to some extent through e-mail and D2L discussions, the faster communication and high degree of use that are associated with Facebook allow for stronger and more expedited reinforcement, theoretically optimizing learning. However, it is important to note that learning was not directly measured here, and that certain conditions are required for Facebook to foster positive academic benefits (Souleles, 2012).

Interestingly, both the amount and level of engagement were positively correlated with academic performance (although these relationships were weak and insignificant), agreeing with the findings of a previous study (Carini et al., 2006). The weakness of the relationships between engagement and performance, however, could mean that lower-performing students were indeed engaging with the material and may benefit from independent online engagement beyond the scope of academic scores. However, Kirschner and Karpinski (2010) reported that Facebook use amongst students resulted in lower GPA and time investment into academic endeavours. Furthermore, Wise et al. (2011) reported that Facebook use in itself (without academic guidance) did not promote academic engagement. Since students were somewhat guided in their use of Facebook in this study for academic purposes (though they were free to engage or not engage), it appears that instructor involvement is critical for insuring the successful use of Facebook in this capacity. Furthermore, the higher amount of student 
engagement with posts that were further commented on by the instructor reinforces this conclusion.

Although performance and engagement were correlated, it is not clear whether higher academic performance leads to enhanced engagement or vice versa. Given that the relationship between cumulative GPA (not including the grade from this course) and engagement was similar to that of course mark and engagement, and that fact that GPA-engagement relationships had a steeper slope than course grade-engagement relationships, it appears as though academic performance may dictate engagement. Further studies are needed, however, to elucidate specific causal relationships between these variables and better understand the role of engagement in modulating academic performance or vice versa.

Although a seemingly positive tool for enhancing overall student engagement, there are negative aspects of using Facebook in this manner. In this study, not all students joined and participated in the Facebook group. This can become a problem if instructors only use Facebook to share additional information. Although using Facebook may enhance overall engagement, individual student engagement could suffer if some students do not use Facebook. Other studies have reported similar problems with implementing Facebook as a learning tool, as uneven access can create a barrier for universal communication and outreach (Bosch, 2009). As such, educators must decide whether reaching all students is more important than maximizing overall engagement. Furthermore, a detailed understanding of class demographics with respect to the number of students active on Facebook can help define which platform(s) to use in order to optimize independent engagement.

Privacy issues surrounding Facebook's educational use are also prevalent (Cain, 2008; MacDonald, Sohn, \& Ellis, 2010). Although Facebook continues to change its privacy regulations, such changes can have unintended and unpredictable consequences for sharing and disclosing information (Christofides, Muise, \& Desmarais, 2009). Although undergraduate students show little concern regarding such issues (Christofides et al., 2009; Debatin, Lovejoy, Horn, \& Hughes, 2009), privacy concerns certainly contribute to the hesitancy of higher education professionals in using Facebook as a learning management system and/or learning environment (Cain, 2008). However, when used informally, privacy issues regarding academic property should be of less concern. Although educators may not want to share personally developed material through platforms like Facebook in the interest of academic confidentiality, additional external material can be easily shared. Furthermore, given Facebook's personal privacy settings and the closed group option, instructors need not worry about their students or other strangers being able to access their personal information (Facebook, 2015).

Instructor involvement also becomes a concern when providing students with additional material to engage with. Before sharing, instructors need to read material and insure that it is relevant and of sufficient quality before providing it to students. Furthermore, when sharing material through multiple platforms, the physical process of sharing material can become time consuming. Using multiple platforms in itself may also be a negative approach. Anecdotally, one student suggested that sharing material on many platforms was overwhelming and felt as though I was spamming them. Consequently, it is critical to understand the most efficient platform for engaging students with additional material to reduce instructor workload and avoid negative aspects of sharing material through too many avenues.

Since Facebook is most often used for social purposes (i.e., chatting/connecting with friends), online multitasking is also a concern. Sana, Weston, and Cepeda (2013) reported that online multitasking can result in hindered learning, as students engaging in online multitasking showed decreased comprehension of lecture material (as measured by test scores), while laptop use itself in the classroom can diminish in-class learning (Fried, 2008). As such, the formal use of Facebook, particularly in the classroom, may be more harmful than helpful. Although linked to diminished lecture comprehension (Sana et al., 2013) and reduced engagement outside of Facebook (Junco, 2011), however, the impact of online multitasking on the comprehension of online material (e.g., additional material shared on Facebook) has yet to be determined. It is also plausible that the use of Facebook outside of the classroom may not have the same impact on comprehension as it does in the classroom. The degree of comprehension and learning through additional material shared on Facebook may be low if students are more interested in, for instance, what their friends are doing on the weekend. However, the results of this study suggest otherwise, given that $23 \%$ of the class engaged to the fullest extent on the Facebook group. Furthermore, such multitasking on Facebook may actually be of benefit to some students outside of the classroom. Anecdotally, one student stated that an interesting post from the class group appeared at random in their Facebook newsfeed as they were using Facebook for social purposes and motivated them to read and engage with the material, rather than interacting socially with friends. Future studies are now needed to determine whether or not online multitasking hinders online material comprehension and whether Facebook use outside of the classroom has the same impact on comprehension as it does in the classroom. 


\section{Conclusion}

The results of this study suggest that Facebook can be used as an online tool for enhancing and optimizing the independent engagement of undergraduate students in a first-year undergraduate science class. This is likely a reflection of the widespread use of Facebook among undergraduate students and hence its convenience and familiarity. However, a detailed understanding of class demographics and knowing what platform is most convenient for a given group of students appears to be of utmost importance in optimizing independent online engagement. The apparent correlation between engagement and academic performance suggests that performance may be a predictor of engagement, or that online engagement may serve to enhance individual course marks - however the specific causal relationship within this correlation requires further assessment. Ultimately, this study suggests that Facebook can be used to enhance extracurricular engagement in a higher education setting and can be beneficial to university students beyond the scope of achievement scores.

\section{Acknowledgements}

I would like to thank all students of the WI/2015 BIOL 1202 class for their cooperation and participation in this study. I would also like to thank Dr. Kate Frego for providing feedback on an earlier version of the manuscript. Finally, I want to thank the Department of Biology and the Teaching and Learning Center at UNB Saint John (especially Dr. Margaret-Anne Smith) for their continued support and guidance.

\section{References}

Aydin, S. (2012). A review of research on Facebook as an educational environment. Educational Technology Research and Development, 60, 1093-1106. http://dx.doi.org/10.1007/s11423-012-9260-7.

Bandura, A. (1977). Social learning theory. New Jersey: Prentice Hall.

Barnett-Queen, T., Blair, R., \& Merrick, M. (2005). Student perspectives of online discussions: Strengths and weaknesses. Journal of Technology in Human Services, 23, 229-244. http://dx.doi.org/10.1300/ J017v023n03 05

Bosch, T. E. (2009). Using online social networking for teaching and learning: Facebook use at the University of Cape Town. Communicatio: South African Journal for Communication Theory and Research, 35, 185-200. http://dx.doi.org/10.1080/02500160903250648

Burge, E. J. (1994). Learning in computer conferenced contexts: The learners' perspective. Journal of Distance Education, 9, 19-43.

Cain, J. (2008). Online social networking issues within academia and pharmacy education. American Journal of Pharmaceutical Education, 72, 10.

Cain, J., \& Policastri, A. (2011). Using Facebook as an informal learning environment. American Journal of Pharmaceutical Education, 75, 207. http://dx.doi.org/10.5688/ajpe7510207

Carini, R. M., Kuh, G. D., \& Klein, S. P. (2006). Student engagement and student learning: Testing the linkages. Research in Higher Education, 47, 1-32. http://dx.doi.org/10.1007/s11162-005-8150-9

Chang, N. (2006). E-discussions as a complement to traditional instruction: Did the students like online communication and why? Journal of Early Childhood Teacher Education, 27, 249-264. http://dx.doi.org/10.1080/10901020600843475

Chen, B., \& Bryer, T. (2012). Investigating instructional strategies for using social media in formal and informal learning. The International Review of Research in Open and Distributed Learning, 13, 87-104.

Christofides, E., Muise, A., \& Desmarais, S. (2009). Information disclosure and control on Facebook: Are they two sides of the same coin or two different processes? CyberPsychology \& Behaviour, 12, 341-345. http://dx.doi.org/ 10.1089/cpb.2008.0226

Cloete, S., De Villers, C., \& Roodt, S. (2009). Facebook as an academic tool for ICT lecturers. Proceedings of the 2009 Annual Conference of the Southern African Computer Lecturers' Association, 16-22. http://dx.doi.org/ 10.114 5/1562741.1562743 
Coates, H. (2006). Student engagement in campus-based and online education: University connections. Oxfordshire: Routledge.

Debatin, B., Lovejoy, J. P., Horn, A. K., \& Hughes, B. N. (2009). Facebook and online privacy: Attitudes, behaviours, and unintended consequences. Journal of Computer-Mediated Communication, 15, 83-108. http://dx.doi.org/ 10.1111/j.1083-6101.2009.01494.x

Deng, L., \& Tavares, N. J. (2013). From Moodle to Facebook: Exploring students' motivation and experiences in online communities. Computers \& Education, 68, 167-176. http://dx.doi.org/10.1016/ j.compedu.2013.04.028.

Esteves, K. K. (2012). Exploring Facebook to enhance learning and student engagement: A case from the University of Philippines (UP) Open University. Malaysian Journal of Distance Education, 14, 1-15.

Facebook. (2015). Terms of Service. Retrieved April 23, 2015, from https://www.facebook.com/legal/terms

Fredricks, J., Blumenfeld, P., \& Paris, A. (2004). School engagement: Potential of the concept, state of the evidence. Review of Educational Research, 74, 59-109. http://dx.doi.org/10.3102/00346543074001059

Fried, C. B. (2008). In-class laptop use and its effects on student learning. Computers \& Education, 50, 906-914. http://dx.doi.org/ doi:10.1016/j.compedu.2006.09.006

Greenhow, C., \& Robelia, E. (2009). Informal learning and identity formation in online social networks. Learning, Media and Technology, 34, 119-140. http://dx.doi.org/10.1080/17439880902923580

Greenhow, C., Robelia, B., \& Hughes, J. E. (2009). Learning, teaching and scholarship in a digital age: Web 2.0 and classroom research: What path should we take now? Educational Researcher, 38, 246-259. http://dx/doi.org/ 10.3102/0013189X09336671

Jones, S., \& Fox, S. (2009). Generations online in 2009. Data memo pew internet and American life project. Retrieved April 22, 2015, from http://www.pewinternet.org/ /media//Files/Reports/2009/PIP_Generations 2009.pdf.

Junco, R. (2011). The relationship between frequency of Facebook use, participation in Facebook activities, and student engagement. Computers \& Education, 58, 162-171. http://dx.doi.org/doi:10.1016/ j.compedu.2011.08.004

Kirschner, P. A., \& Karpinski, A. C. (2010). Facebook and academic performance. Computers in Human Behavior, 26, 1237-1245. http://dx.doi.org/doi:10.1016/j.chb.2010.03.024

MacDonald, J., Sohn, S., \& Ellis, P. (2010). Privacy, professionalism, and Facebook: A dilemma for young doctors. Medical Education, 44, 805-813. http://dx.doi.org/10.1111/j.1365-2923.2010.03720.x

Manca, S., \& Ranieri, M. (2013). Is it a tool suitable for learning? A critical review of the literature on Facebook as a technology-enhanced learning environment. Journal of Computer Assisted Learning, 29, 487-504. http://dx.doi.org/10.1111/jcal.12007

Moran, M., Seaman, J., \& Tinti-Kane, H. (2011). Teaching, learning, and sharing: How today's higher education faculty use social media. Boston, MA: Pearson Learning Solutions.

Mori, I. (2007). Student expectations study 2007. Coventry: Joint information systems committee. Retrieved April 22, 2015, from http://www.jisc.ac.uk/media/documents/publications/studentexpectations.pdf

Nemec, L., Holb, M., Burkeljca, J., \& Welzer, T. (2011). Facebook as a teaching tool. Proceedings of the 22nd EAEEIE Annual Conference, 1-4.

Pemberton, A. (2011). From friending to research: Using Facebook as a teaching tool. College \& Research Libraries News, 72, 28-30.

R Development Core Team. (2012). R: A language and environment for statistical computing. Vienna: $\mathrm{R}$ Foundation for Statistical Computing.

Said, M. N. H. M., Tahir, L. M., \& Ali, M. F. (2014). Facebook as a tool: Exploring the use of Facebook in teaching and learning. 2014 International Conference on Teaching and Learning in Computing and Engineering, 1, 120-124. http://dx.doi.org/10.1109/LaTiCE.2014.29

Sana, F., Weston, T., \& Cepeda, N. J. (2013). Laptop multitasking hinders classroom learning for both users and nearby peers. Computers \& Education, 62, 24-31. http://dx.doi.org/doi:10.1016/j.compedu.2012.10.003

Selwyn, N. (2009). Faceworking: Exploring students' education-related use of Facebook. Learning, Media and 
Technology, 34, 7-174. http://dx.doi.org/10.1080/17439880902923622

Sharan, S., \& Chin, T. I. G. (2008). Student engagement in learning. In S. Sharan, \& I. G. C.Tan (Eds.), Organizing schools for productive learning (pp. 41-45). Netherlands: Springer.

Souleles, N. (2012a). An action research project on the use of Facebook in an undergraduate visual communication study unit. Art, Design \& Communication in Higher Education, 11, 127-141. http://dx.doi.org/10.1386/ adch.11.2.127_1

Souleles, N. (2012b). Perceptions of undergraduate Graphic Design students on the educational potential of Facebook. Research in Learning Technology, 20, 241-252. http://dx.doi.org/10.3402/rlt.v20i0.17490

Sturges, M. (2012). Using Facebook as a teaching tool in higher education settings: Examining potentials and possibilities. International conference on the future of education. 2nd conference edition. Retrieved March 30, 2015, from http://conference.pixel-online.net/edu_future2012/common/download/Paper_pdf/ 182-EL10-FP-Sturges-FOE2012.pdf

Usluel, Y. K., \& Mazman, S. G. (2009). Adoption of Web 2.0 tools in distance education. Procedia-Social and Behavioral Sciences, 1, 818-823. http://dx.doi.org/doi:10.1016/j.sbspro.2009.01.146

Wang, J., Lin, C. F. C., Yu, W. C. W., \& Wu, E. (2013). Meaningful engagement in Facebook learning environments: Merging social and academic lives. Turkish Online Journal of Distance Education, 14, 302-322.

Wellborn, J. G. (1991). Engaged and disaffected action: The conceptualization and measurement of motivation in the academic domain (unpublished doctoral dissertation). University of Rochester, New York, USA.

Whipp, J. L. (2003). Scaffolding critical reflection in online discussions: Helping prospective teachers think deeply about field experiences in urban schools. Journal of Teacher Education, 54, 321-334. http://dx.doi.org/ 10.1177/0022487103255010

Wise, L., Skues, J., \& Williams, B. (2011). Facebook in higher education promotes social but not academic engagement. Proceedings ascilite 2011 Hobart, 1332-1342.

\section{Copyrights}

Copyright for this article is retained by the author(s), with first publication rights granted to the journal.

This is an open-access article distributed under the terms and conditions of the Creative Commons Attribution license (http://creativecommons.org/licenses/by/3.0/). 